\title{
Los hechos de mayo de 1937: efectivos y bajas de cada bando ${ }^{1}$
}

\author{
Manuel Aguilera Povedano \\ CESAG, Universidad de las Islas Baleares
}

RESUMEN: Las víctimas de los Hechos de Mayo de 1937 en Barcelona fueron identificadas por los historiadores Josep Solé y Joan Villarroya en 1982 pero desde entonces nadie ha tratado de revisar ni ampliar los datos de este listado. Gracias a una nueva consulta de todas las fuentes, el autor ha logrado, además de hacer un cálculo aproximado de los efectivos que participaron, identificar el bando de la mayoría de dichas víctimas, algo que no se había hecho antes. El hallazgo de un documento inédito que contiene el listado de bajas que sufrieron la UGT, el PSUC y las JSU ha sido clave para resolver la incógnita. El resultado dice que el bando revolucionario (anarquistas y el POUM) sufrió más del doble de bajas que el gubernamental debido a que su enemigo ocupaba una posición defensiva.

\section{Palabras Clave: Hechos de Mayo; Guerra Civil Española; Revolu- ción; Anarquismo; Comunismo.}

\section{The Facts of May 1937: Militants and Victims in Each Side}

ABSTRACT: The victims of the Barcelona events of May 1937 were identified by the historians Josep Solé and Joan Villarroya in 1982 but since then nobody has tried to look through or extend the contents of this list. Thanks to a new review of the archives, the author has succeeded, besides to make a rough estimate of the militants who taked part, in identifying the side of most of the mentioned victims, something which has not been done before. The discovery of a unpublished document with the UGT, PSUC and JSU victims list has been the key to solve the mystery. The result says that

1 Siglas: CDMH: Centro Documental Memoria Histórica. FAL: Fundación Anselmo Lorenzo. AHPCE: Archivo Histórico del PCE. ANC: Archivo Nacional de Cataluña. HIA: Hoover Institution Archives. AHM: Archivo Histórico Militar. AHCB: Archivo Histórico de la Ciudad de Barcelona. 
the revolutionary side (anarchists and POUM) suffered more than twice casualties than the government side because their enemy occupied a defensive position.

KEY WORDS: May Events; Spanish Civil War; Revolution; Anarchism; Communism.

Los Hechos de Mayo son un episodio clave en la Guerra Civil Española del que, inexplicablemente, se ha hecho poco trabajo científico. Con ello queremos decir que la historiografía ha abordado y discutido ampliamente sus aspectos políticos pero ha pasado de puntillas ante los medios, los combates y las víctimas. En definitiva, los Hechos en sí no se han tratado todavía de manera detallada. Ocurre lo mismo con otro de los combates urbanos que libraron los antifascistas entre sí: el golpe de Casado. Los archivos tienen todavía mucho que aportar al respecto y, al contrario de lo que pudiera parecer, hay abundante información inédita que permite desarrollar una labor científica y aportar grandes novedades.

Como afirma Ferrán Gallego, los Hechos de Mayo tienen una «validez universal» y su significado está todavía vigente ${ }^{2}$. No se consideraban «un tema del pasado», como él explica, en la Transición, ni lo son ahora porque son el mejor ejemplo de la división antifascista y de los problemas de unidad que han caracterizado siempre a la izquierda. El debate está servido y la historiografía sobre el tema es un buen ejemplo de ello. En efecto, este episodio es tremendamente importante porque revela el proceso revolucionario que se puso en marcha el 19 de julio de 1936 y las profundas disensiones entre las facciones antifascistas a la hora de afrontarlo. No hubo un bando antifascista sino varios y la República no supo mantenerlos cohesionados porque, sencillamente, no pudo satisfacer las aspiraciones de todos. Payne ha escrito que «la Guerra Civil exigió un constante proceso de ajuste en toda la izquierda, porque habían creado una situación revolucionaria distinta para cada una de sus diferentes utopías, imaginaciones y proyecciones» ${ }^{3}$. La revolución era algo irrenunciable e improrrogable para los anarquistas y el POUM, así que todas las «marchas atrás» que se realizaron desde el Gobierno en los primeros meses de 1937 prepararon el escenario para la confrontación.

La historiografía divide a los dos bandos entre revolucionarios y los llamados despectivamente «contrarrevolucionarios», ese apelativo que Gallego excluye de todo antifascista aunque otros como Bolloten, Aisa o Amorós lo utilizan con normalidad para referirse a los estalinistas de $1936^{4}$. Es cierto que

2 En MARTÍN RAMOS, 2010: 12 y 17.

3 PAYNE, 2010: 234.

4 BOLLOTEN, 2004. AMORÓS, 2003. AISA, 2007. 
tanto el PCE como el PSUC y buena parte de la UGT catalana abrazaron la tesis estalinista de postergar el inicio de la revolución, pero eso no significa que dejaran de creer en ella. La revolución socialista podía esperar. Por ello, creemos que es más adecuado llamar a su bando «gubernamental», es decir, adepto de la Generalitat que dirigía Lluís Companys, defensor de la propiedad privada, el pequeño comerciante y, en definitiva, el statu quo republicano. Es cierto que los anarquistas estaban representados en el gobierno pero su peso era cada vez menos importante y las últimas decisiones contravenían el espíritu de la revolución libertaria, así que defender al gobierno era, para el auténtico revolucionario, defender la «contrarrevolución».

La pugna entre partidarios y contrarios a la revolución social que defendían los anarquistas fue especialmente acusada en Cataluña. Como explica Gallego, ya en diciembre de 1936 el líder del PSUC, Joan Comorera, creía que había que acabar con las actitudes de un gobierno campesino que promovía el POUM y con el poder de los comités que planteaba la CNT-FAI. Como consejero de Abastos fue maniobrando para aislar a la CNT-FAI y lanzó una ofensiva «virulenta» de desprestigio de sus experimentos colectivistas en el campo, a los que acusaba de los problemas de abastecimiento de Barcelona. Gallego reconoce que el PSUC urdió una trama para controlar los órganos de poder más relevantes para la marcha de la guerra ${ }^{5}$. Las actas de las reuniones de los comités del PSUC de Barcelona en los primeros meses de 1937 son concluyentes en este sentido ${ }^{6}$.

El 16 de diciembre se disolvió el gobierno de unidad de la Generalitat y se excluyó por primera vez a un partido antifascista con suficiente representación. Gallego y Martín Ramos coinciden en el error del PSUC al maniobrar para apartar al POUM. Gallego dice estar «convencido» de que si se hubiera mantenido el gobierno de unidad las cosas «no habrían llegado tan lejos» ${ }^{7}$. El POUM fue «la principal víctima del proceso de exclusión, la más fácil, la más rápida, la más visiblemente prescindible» ${ }^{8}$. La CNT era otra cosa. Aunque su afiliación había descendido en los últimos años, seguía siendo la fuerza obre-

5 GALLEGO, 2007: 329-355.

6 Acta de la reunión ordinaria del Comité de Barcelona del PSUC. 23 de marzo de 1937. AHPCE. Documentos PCE. Carpeta 18. p. 2; y CDMH PS Madrid. Caja 540 (2) no 140; Acta de la reunión de la célula 15 del PSUC. Barcelona, 25 de abril de 1937. CDMH PS Barcelona. Caja 178 n $^{\circ}$ 29; Acta de la reunión ordinaria del Comité de Barcelona del PSUC el 27 de abril de 1937. AHPCE. Documentos PCE. Carpeta 18; y CDMH PS Madrid. Caja 540 (2) no 140; Expuse más ampliamente el contenido de estas actas en la comunicación «Causas de los sucesos de mayo de 1937 en Cataluña». En BULLÓN DE MENDOZA, A, TOGORES, L.E., 2008: 270-283.

7 En MARTÍN RAMOS, 2010: 24; y GALLEGO, 2007: 286.

8 GALLEGO, 2007: 330. 
ra mayoritaria en Cataluña. Su exclusión se debía hacer con mucha mayor sutileza y, sobre todo, inteligencia.

Los anarquistas sabían a lo que se exponían. En su prensa puede verse claramente cómo tenían muy presente lo sucedido en la Revolución Rusa, donde los anarquistas de Néstor Majnó habían sido barridos por los bolcheviques después de haber sido compañeros de armas en la lucha contra el zarismo. Tampoco olvidaban cómo en 1921 el Ejército Rojo había reprimido la rebelión de los marineros de Kronstadt ${ }^{9}$. No obstante, estaban contra la espada y la pared. Tenían al ejército franquista enfrente avanzando día a día posiciones y detrás una serie de organizaciones que se unían de una forma tácita para dar un giro radical a la vida en la retaguardia. PSUC, ERC, UGT y Unió de Rabassaires fueron acercando posturas para aislar a los revolucionarios. Preston indica que los anarquistas podían ganar «si emprendían una guerra a cualquier precio contra el resto de fuerzas republicanas $\rangle^{10}$. Pero claro, con Franco al otro lado, resultaba algo suicida.

Los militantes de base del movimiento libertario vieron cómo sus líderes tenían que ir renunciando poco a poco al dogma puramente anarquista. Aceptaron la eliminación del Comité de Milicias Antifascistas, la incorporación al gobierno como consejeros y ministros, el decreto de colectivizaciones, la imposición de la disciplina, el control policial, la militarización de las milicias, etcétera. Sus adversarios tampoco querían que controlaran la Telefónica y cuando fueron a retirársela por la fuerza estalló la guerra. José Luis Martín Ramos dice en su libro que la paciencia de la CNT-FAI estaba ya agotada en enero de $1937^{11}$. Los libertarios sabían que no se iban a volver a encontrar una ocasión como aquella así que concluyeron que había que defender la revolución a toda costa. Los sucesos se agravaron en las semanas siguientes, con choques terribles en numerosos pueblos catalanes como el de La Fatarella, que dejó 35 muertos. El enfrentamiento abierto parecía inevitable así que ambos bandos se prepararon para la batalla.

Como se puede apreciar en su prensa y en su documentación interna, tanto la CNT-FAI como el PSUC preveían desde principios de 1937 un combate en Barcelona $^{12}$. Los anarquistas apenas se prepararon por su imprudente subes-

9 Poco antes de los Hechos de Mayo, el anarquista Camilo Berneri había publicado un artículo en el periódico Guerra di Clase en el que afirmaba que «si no estuviera Madrid en fuego y llamas, podría conjurarse Kronstadt». En SOUCHY, 1937: 26-28.

10 PRESTON, 2011: 534.

11 MARTÍN RAMOS, 2012: 339.

12 Véase por ejemplo La Batalla, 17 de marzo de 1937, p. 2 y 21 de marzo de 1937, p. 6. Nosotros, 12 de marzo de 1937, p. 1, y 7 de abril de 1937, p. 2. CNT, 22 de marzo de 1937, p. 2. Boletín de Información CNT-FAI, 30 de marzo de 1937, p. 3. Carta del secretario de las JJLL de Agullana al Comité Regional de las JJLL de Cataluña. 9 de marzo de 1937. Carta del Comité Regional de las JJLL de Cataluña al secretario de las JJLL de Agullana. 12 de marzo 
timación del enemigo mientras que los comunistas llevaron a cabo un plan muy minucioso. Prueba de ello es el acta de la reunión del comité de Barcelona del PSUC del 23 de marzo y las referencias que hay en los archivos sobre la compra de armas que hizo este partido a espaldas de los gobiernos central y catalán en Francia. La bibliografía específica nos ha ofrecido hasta ahora hasta tres indicios de este acopiamiento clandestino que tenía como objetivo «dar batalla a la FAI». Se trata del testimonio de tres espías de distinta procedencia: uno es agente de Negrín, otro de la CNT y el otro de los servicios de inteligencia británicos ${ }^{13}$. El archivo histórico del PCE eleva el rango de indicio a prueba gracias a unos documentos inéditos que guarda. Son los informes de los propios militantes del PSUC que participaron en el contrabando de armas. Un manuscrito anónimo de un militante de Figueras explica cómo desde enero de 1937 compraban las armas y las llevaban a Barcelona a escondidas de la CNT. Cuenta que en una de estas misiones llevaron dos ametralladoras, diez automáticas y 20 pistolas a la sede de la UGT de la Banca, que sirvieron para defender el local durante los Hechos de Mayo ${ }^{14}$.

Otro informe revela que el PSUC de Barcelona había creado una Comisión de Defensa formada por tres de sus dirigentes con el objetivo «de tomar medidas de organización y de defensa para la lucha contra los elementos anarcotrotskistas». Uno de sus miembros escribió que su tarea era «organizar en los lugares de trabajo a grupos de camaradas que se les preparaba y se les instruía en el manejo de la ametralladora, fusil y bombas de mano». Afirma que estaban en connivencia con la fuerza pública y la UGT para unir sus fuerzas durante los combates ${ }^{15}$.

de 1937. Carta de las JJLL de Banyoles al Comité Regional de JJLL de Cataluña. Banyoles, 24 de marzo de 1937. PS Barcelona: caja 140 n 1. CDMH. SÁNCHEZ CERVELLÓ, 2006: 107. Informe del vicejefe del GRU en España, Nikonov, a Moscú. 20 de febrero de 1937. En RADOSH, HABECK, G. SEVOSTIANOV, 2002: 177-8.

13 Acta de la reunión ordinaria del Comité de Barcelona del PSUC, 23 de marzo de 1937, CDMH, PS Madrid, caja 540 (2), n 140. OLAYA MORALES, 1998: 10. VIÑAS, 2007: 340n. SÁNCHEZ CERVELLÓ, 2006: 121-31. Un informe de la CNT dice que ERC también estaba comprando armas en Suiza. Alberto Oller, «Mis opiniones del proceso de Berna», 9 de agosto de 1938, FAL, Informes sobre actividades comunistas, Documentos CNT, documentación sin inventariar.

14 Anónimo, «Cómo nos hicimos con armas», Moscú, 9 de noviembre de 1963, AHPCE, Manuscritos, tesis y memorias, sig. 24/13.

15 José Castelo, «El putch de mayo de 1937 en Barcelona», 4 de noviembre de 1963, AHPCE, Tesis, manuscritos y memorias, sig. 24/3. Cuando hablamos de fuerza pública nos referimos a todos los cuerpos de seguridad del Estado salvo las Patrullas de Control, es decir, guardias de asalto, guardias nacionales republicanos, mossos d'esquadra y agentes de seguridad e investigación. 


\section{EFECTIVOS Y ARMAMENTO}

Es difícil saber cuántos militantes, fuerza pública y soldados había en aquel momento en Barcelona. La ciudad tenía en 1936 alrededor de un millón de habitantes y en unos meses se había llenado de refugiados y visitantes extranjeros ${ }^{16}$, muchos de los cuales participaron activamente en los Hechos de Mayo. Hasta ahora no se ha hecho ningún estudio empírico que lo demuestre, quizá por su alta complejidad, pero sí podemos hacer una aproximación. Un informe anónimo asegura que la Guardia de Asalto contaba con unos 2.000 efectivos más 600 agentes desarmados, además de varios cientos de guardias nacionales republicanos y algunos mossos d'esquadra y agentes de seguridad e investigación ${ }^{17}$. La UGT tenía unos 86.000 afiliados en Cataluña ${ }^{18}$ y el PSUC 13.000 sólo en Barcelona -la mayoría también miembros de la UGTpero muchos de ellos estaban en el frente o permanecieron inactivos durante los combates. El cónsul soviético Antonov Ovseenko ha escrito que el PSUC movilizó a 2.000 militantes armados con 1.000 fusiles, 50 fusiles ametralladores y 20 ametralladoras pesadas ${ }^{19}$. Por su parte, ERC, Estat Català y Acció Catalana Republicana aportaron una pequeña cantidad de hombres -no más de 200 - teniendo en cuenta las pocas bajas que sufrieron ${ }^{20}$.

Los gubernamentales recibieron además el refuerzo de dos contingentes venidos de fuera. Uno fue la Columna Carlos Marx casi al completo alrededor de 2.000 hombres- y el otro un pequeño grupo de las milicias alpinas de Huesca ${ }^{21}$. En total, los efectivos de este bando sumaban unos 7.500 pero no toda la fuerza pública ni toda la Columna Carlos Marx fueron movilizados así que la cifra real de participantes debió estar en torno a los $5.000^{22}$.

El número de militantes de la CNT-FAI en aquel momento en Barcelona también es una incógnita. El sindicato se atribuye un millón y medio de afi-

16 Ferran Gallego habla de 300.000 refugiados a finales de 1936 y de 80.000 mendigos y milicianos desempleados en Barcelona. GALLEGO, 2007: 331.

17 Informe anónimo, ANC, Fondo Generalitat de Catalunya (Segona República), Dossier Fets de Maig, Ref. 1614.

18 MARTÍN RAMOS, 2010.

19 VIÑAS, 2007: 500.

20 Sólo cuatro víctimas mortales, como veremos más adelante.

21 BERTRÁN Y MUSITU, 1940: 24. Estas milicias alpinas eran conocidas como «las margaritas de Companys» porque su distintivo era la flor alpina edelweiss. Estaban compuestas principalmente por afiliados a Estat Català y se habían enfrentado ya a los anarquistas en La Molina y Moià. Fue disuelta poco antes de los Hechos de Mayo en Aragón y trasladada a Barcelona. Mortera Pérez, Artemio, «La compañía de esquiadores de las Milicias Pirenaicas», en http://www.nevasport.com/reportajes/art/31728/Esquiadores-en-la-Guerra-Civil-Espanola-

I/imprimir/. Gascón Ricao, Antonio, «Unidades Vasco Catalanas en La Guerra Civil Española», en http://www.sbhac.net/Republica/Fuerzas/EPR/EprD/VascoCatalanas.htm[octubre 2011].

22 La Columna Carlos Marx apenas salió del cuartel Voroshilov. 
liados en 1937 en España, de los cuales medio millón pertenecería sólo a la regional catalana. Sin embargo, el último recuento oficial que se hizo en el Congreso de Zaragoza un año antes daba la cifra de 550.595 afiliados en toda España. Cataluña tenía 142.789 -más 43.363 de los sindicatos de oposicióny sólo Barcelona 87.860, prácticamente una tercera parte de los que tenía en $1931^{23}$.

En cualquier caso, la fuerza de los anarquistas era aplastantemente más poderosa que la de cualquiera de sus adversarios, pero ¿podría contar con toda ella en caso de enfrentamiento? Los hechos demostraron que no. Durante los combates de mayo sí se movilizaron casi al completo las Juventudes Libertarias y muchos anarquistas extranjeros, sobre todo italianos y alemanes. Había muchos jóvenes que se habían perdido los combates del 19 de julio y no querían dejar pasar la oportunidad de defender la revolución en la calle. Las Juventudes Libertarias tuvieron un peso extraordinariamente importante. De hecho, fue la única organización libertaria «oficial» que animó la lucha desde sus comités de distrito. Llegó incluso a intentar reanudarla cuando ya se había terminado ${ }^{24}$. Entre los no oficialistas estaban Los Amigos de Durruti, que según su dirigente Jaime Balius y el historiador Miquel Amorós tenían en mayo entre 4.000 y 5.000 afiliados, aunque a la vista de los hechos movilizaron sólo a varios cientos ${ }^{25}$. Sí participaron al completo en los combates las Patrullas de Control, que en aquel momento estaban formadas por 890 miembros que sólo respondían ante la CNT-FAI y el POUM ${ }^{26}$.

Este bando contó también con varios refuerzos venidos de fuera. El 3 de mayo por la mañana llegó procedente de Madrid la Columna Tierra y Libertad al completo -unos 2.500 hombres-27. La unidad no participó íntegramente

23 TAFUNELL, CARRERAS, 2005: 1139. PEIRATS, 1988: 117.

24 Véase por ejemplo «Notas del diario de Berdinz [Berzin] sobre la situación en Cataluña en el Putch de 1937», AHPCE, Tesis, manuscritos y memorias, sig. 24/6. Manifiesto de las Juventudes Libertarias de Gracia a los auténticos Revolucionarios, Barcelona mayo de 1937, ANC, Fondo Generalitat de Catalunya (Segona República), Dossier Fets de Maig. Ref. 1614. Véase también el episodio que cuenta Orwell del tiroteo que trató de iniciar en las Ramblas un «chico con mono azul». ORWELL, 2000: 134-5.

25 Cartas de Jaime Balius del 10 y 24 de junio de 1946 a Burnett Bolloten, HIA, Bolloten Collection, caja 5 carpeta 9. MINTZ, PECIÑA, 1978: 10. AMORÓS, 2003: 245.

${ }^{26} \mathrm{La}$ cifra la ha comprobado recientemente José Luis Ledesma en ESPINOSA (ed.), 2010: 198. Sufrieron 17 muertos y 40 heridos en los combates. PSUC, UGT y ERC abandonaron las patrullas en marzo de 1937.

27 Creemos que exagera el miliciano Aldo Aguzzi al afirmar que el cuartel Spartacus estaba ocupado por 5.000 milicianos anarquistas. Aguzzi ha escrito que se guarecían la Columna Tierra y Libertad al completo, 200 italianos y algunas decenas más de otras nacionalidades. Contaban con 20 piezas de artillería, 16 autos blindados y una ametralladora. Había llegado de Madrid esa mañana, comandada por el anarquista Ceva, aunque esos días su jefe accidental fue Ricardo Sanz, comandante de la 26 División (Columna Durruti). AGUZZI, 2006: 155. 
en la lucha pero sí fue mucho más activa que la Columna Carlos Marx y aportó 15 vehículos blindados que fueron claves en los asaltos a locales enemigos. No hay constancia de que esta unidad fuera enviada aposta a Barcelona para participar en el enfrentamiento y parece que su presencia era casual. De hecho, los anarquistas se veían con la fuerza suficiente para ganar la batalla sin recibir refuerzos de fuera. En aquel momento había además pequeños grupos de combatientes que estaban de descanso en Barcelona, como 50 milicianos de la Columna Durruti que cubrieron la mítica «Brecha de San Pablo» (en la avenida del Paralelo) y tres centurias de fortificaciones de la CNT $\left(2^{\mathrm{a}}, 3^{\mathrm{a}}\right.$ y $\left.6^{\mathrm{a}}\right)$ que acababan de llegar de permiso procedentes de Montalbán (Teruel) ${ }^{28}$.

El POUM, como ERC, ocupó sólo unos pocos edificios durante los Hechos y levantó algunas barricadas así que su aportación no debió de superar el par de centenares de hombres. Quizá poseía algunos más pero es difícil identificarlos porque la gran mayoría se mantuvo a la defensiva en sus propios edificios ${ }^{29}$. Orlov asciende esta cifra y da al bando revolucionario 1.000 poumistas más 3.000 de la CNT y 1.500 de la $\mathrm{FAI}^{30}$. Sin embargo, entre todos los informes creemos que el que se acerca más a la realidad es el de un agente del NKVD apodado Goratsy. Afirma que los revolucionarios tenían entre 7.000 y 7.500 hombres y los gubernamentales entre 4.500 y 5.000 .

En cuanto al armamento, el agente apunta que ambos poseían revólveres, fusiles, ametralladoras y bombas de mano ${ }^{31}$. El comunista Jesús Hernández ha escrito, sin duda exagerando, que los anarquistas tenían en Barcelona «30.000 fusiles, 400 ametralladoras, docenas de miles de bombas de mano, 30 morteros de trinchera e incalculables pistolas automáticas $\rangle^{32}$. Goratsy, en cambio, no iba mal encaminado tampoco respecto al armamento. Ambos bandos contaron con pistolas, fusiles, granadas, morteros y artillería ligera. Los anarquistas utilizaron varios cañones que incautaron al comenzar los combates y los carros blindados de la Columna Tierra y Libertad. Dos dirigentes anarquistas han reconocido que en la retaguardia catalana había 60.000

28 SINCA VENDRELL, 1980: 55-6. Solidaridad Obrera, 8 de mayo de 1937, p. 10.

29 El POUM sufrió también sólo cuatro bajas mortales. Los edificios que defendieron fueron el consulado italiano, el Cinema Poliorama, la sede del comité ejecutivo en Las Ramblas, el Palau de la Virreina, la redacción de La Batalla, el hotel Principal Palace y el hotel Falcón.

30 VIÑAS, 2007: 499.

31 «Notas del diario de Berdinz [Berzin] sobre la situación en Cataluña en el Putch de 1937». Véase también el Informe de Codovilla a Dimitrov y Manuilski. 11 de mayo de 1937, en RADOSH, HABECK, G. SEVOSTIANOV, 2002: 248. Informe del agente Juan Ferrando Martínez a Francisco Galán, jefe de la 39 División, Cedrillas, 1 de julio de 1937, CDMH, PS Barcelona, caja 397, $\mathrm{n}^{\circ} 5$.

32 HERNÁNDEZ, 1946: 204. 
fusiles y en el frente sólo 30.000. También que había muchas más ametralladoras en las ciudades que en las trincheras ${ }^{33}$.

Las columnas anarquistas del frente llegaron a movilizar el día 4 una fuerza de unos 1.500 hombres de la 28 División (antigua Columna Ascaso), que se unieron a 300 poumistas de la 29 División (Columna Lenin) y pusieron rumbo a Barcelona pero fueron detenidos en Binéfar (Huesca). Allí recibieron órdenes de sus compañeros de Barcelona de no abandonar el frente porque tenían fuerzas suficientes para ganar la batalla, así que dieron media vuelta y regresaron al frente ${ }^{34}$.

No obstante, un grupo de soldados de la 25 División actuó por su cuenta e intentó llegar a la retaguardia. Abandonó el frente dirigiéndose a Cataluña desde Teruel y ocuparon poblaciones como Monroyo, Valderrobres (Teruel) y Morella (Castellón) hasta que fueron detenidos por una avanzadilla de la fuerza pública enviada desde Valencia ${ }^{35}$.

Esta aproximación nos lleva a concluir que el bando revolucionario contó con una cantidad superior de efectivos -al menos un $40 \%$ más- que inclinaba la balanza a su favor. La Generalitat fue consciente de ello desde el principio y el mismo día 3 de mayo pidió al Gobierno central que le enviara urgentemente el refuerzo de 1.500 guardias de asalto ${ }^{36}$. Los ministros de Defensa y Gobernación, Indalecio Prieto y Ángel Galarza, respectivamente, tardaron en reaccionar pero a la vista de los acontecimientos y el peligro que corrían no sólo Lluís Companys sino el presidente Azaña -que se refugiaba en el Parlament- pusieron en marcha un enorme contingente. El día 5 de mayo desembarcaron en Barcelona 850 marineros que se pusieron a las órdenes de la Generalitat aunque apenas participaron en los combates. Según los propios revolucionarios, «la marina española era neutral, incluso tendía a simpatizar con la revolución» ${ }^{37}$. Los días 7 y 8 llegaron con el fin de los combates 5.000

33 PEIRÓ, 1987: 35. ABAD DE SANTILLÁN, 1977: 111.

34 Entrevista a José Duque en Guadalajara, México, en noviembre de 1979, p. 54, CDMH, Exilio Español en México, nº 38. BERTRÁN Y MUSITU, 1940: 24. El soldado de la Columna Roja y Negra Pedro Torralba asegura que «a ninguna de las unidades de la 127 Brigada se le ordenó desguarecer ni un metro de trinchera». TÉLLEZ SOLÁ, 1966: 49-50. TORRALBA CORONAS, 1980: 115-6.

35 «Informe que emite la Asesoría Jurídica del frente de Aragón en virtud de la orden telegráfica del general jefe del Ejército del Este», 15 de mayo de 1937, AHM, Zona Roja, Armario 62 Legajo 768 Carpeta 1, Rollo 71.

36 «Crònica diària de les activitats del President Companys: mes de maig», 1937, ANC, Fondo Generalitat de Catalunya (Segona República), ref. 7486.

37 OEHLER, 2006: 43. La Batalla, 8 de mayo de 1937: 2. BOLLOTEN, 2004: 671-2. MARTÍNEZ BANDE, 1989: 264. 
guardias de asalto procedentes de Madrid y Valencia más una pequeña unidad de carabineros y seis piezas de artillería $^{38}$.

Las fuentes nos revelan que aunque los bandos movilizaron a miles de hombres, sólo una pequeña parte estuvo firmemente comprometida y permaneció activa durante los cuatro días que duraron los combates. La gran mayoría prefería no buscar el enfrentamiento y mantenerse a la defensiva. Incluso hubo quien abandonó su puesto por oponerse a una lucha entre antifascistas. Un ejemplo fue lo que ocurrió en la sede del GEPCI (patronal de comerciantes afín al PSUC) de la plaza Urquinaona. Allí se concentraron el 3 de mayo por la tarde 15 militantes del PSUC y 25 del sindicato Textil de la UGT y cuando valoraron la situación algunos decidieron abandonar porque no querían luchar contra la CNT «para defender a los burgueses». Otros se marcharon porque sólo había bombas de mecha y «seis o siete» pistolas para todos ${ }^{39}$. Los bandos, sobre todo el revolucionario, también perdieron muchos hombres cuando los líderes de la UGT y la CNT les exigieron por la radio el 4 de mayo que abandonaran el combate ${ }^{40}$.

Los dos contendientes contaban con numerosos hombres y el devenir de los acontecimientos les trajo problemas de intendencia que no esperaban. Los militantes tuvieron que permanecer sin salir de un mismo edificio durante varios días y sufrieron una fuerte escasez de comida. Los defensores de la sede central del PSUC (hotel Colón) y del Café Moka-Radio Associació, en Las Ramblas, se vieron obligados a organizar expediciones en busca de víveres. Por su parte, los anarquistas que resistían en los pisos superiores de la Telefónica tuvieron que rendirse el día 6 porque no aguantaban ya el hambre ${ }^{41}$.

38 Transcripción conferencia Galarza-Montseny, 7 de mayo de 1937, ANC, Dossier Fets de Maig, Fondo Generalitat de Cataluña (Segona República), $n^{\circ}$ 1, Ingreso 1614. «Crònica diària de les activitats del President Companys: mes de maig». La Batalla, 8 de mayo de 1937, p. 2 , y 9 de mayo de 1937, p. 4. La Vanguardia, 8 de mayo de 1937, pp. 2 y 3, y 9 de mayo de 1937 , p. 3.

39 J. Olivo, «Informe sobre l'actuació, durant els dies 3 al 10 del corrent, dels camarades enviats per el Partit al local de la GEPCI", 9 de mayo de 1937, y Luis Córdoba, «Informe del radi Torrassa al Comité de Barcelona», CDMH, PS Madrid, caja 540 (2) n 146.

40 La Vanguardia, 5 de mayo de 1937, p. 2.

41 «Informe del radi III al Comité de Barcelona», y Amadeu Fabré, «Informe elevat al Comité Local del PSU pel radi VI", 12 de mayo de 1937, CDMH, PS Madrid, caja 540 (2) n 146. Declaraciones de Teodor Garriga, documental «Zona Roja», emitido en el Canal 33 el 12 de enero de 2005, Televisió de Catalunya. Manuel del Caso, «El putch de mayo de 1937. Recuerdos de Del Caso», AHPCE, Tesis, manuscritos y memorias, sig. 24/2, pp. 3-4. BONAMUSA, 16 (Barcelona, 1977): 6. 


\section{LAS VÍCTIMAS DE CADA BANDO}

Uno de los puntos esenciales en los Hechos de Mayo es el número de víctimas que hubo en los combates de Barcelona ciudad ${ }^{42}$. Las primeras pistas que se dieron sobre ello se publicaron en 1970. En aquel año Martínez Bande publicó las que hubo en toda Cataluña basándose sólo en la prensa de la época y le salían 216 muertos y 340 heridos. A él le parecían pocas y señaló que habría que añadir las resultantes de «las terribles represalias inmediatas». Casi a la vez se publicó el libro del periodista Manuel Cruells, que se basó en la cifras oficiales que dio la Generalitat justo después de los sucesos y que elevaban la cantidad a 500 muertos y 1.000 heridos. Al contrario que Bande, este testigo de los Hechos apuntó acertadamente que le parecían muchas debido a «la naturaleza defensiva» que tuvo la lucha y señalaba que la mayoría de las víctimas se habían producido por asesinatos y no por los combates ${ }^{43}$.

En 1977 Ramón Salas Larrazábal volvió a tratar el tema y aportó la cifra de muertes violentas en Barcelona durante todo el mes de mayo de 1937 que daba el Instituto Nacional de Estadística: 498. Sin embargo, como experto militar, apuntaba que era un número muy elevado y que el real no debió de superar el par de centenares ${ }^{44}$. Cinco años después, en 1982, Josep Solé y Joan Villarroya saldaron la polémica. Estos historiadores realizaron una investigación a fondo de todas las fuentes: el Registro Civil de Defunciones de Barcelona, el Registro del Depósito Judicial, el Registro de Cementerios y la prensa diaria. Obtuvieron 218 nombres de víctimas registradas en Barcelona entre el 3 y el 11 de mayo de $1937^{45}$. El enigma quedó resuelto pero, sorprendentemente, desde entonces sólo un autor de todos los que han escrito ampliamente sobre los Hechos de Mayo ha citado este listado: Ferrán Gallego en su libro Barcelona, mayo de 193746. El año 2007, setenta aniversario de los sucesos, ha sido prolífico en obras sobre el tema pero hasta cuatro autores (Viñas, Aisa, Amorós y Guillamón) han pasado por alto este importante trabajo ${ }^{47}$.

La labor de Solé y Villarroya es encomiable no sólo porque pone nombres y apellidos a las víctimas, sino porque aporta datos imprescindibles para una reconstrucción de los combates. Da fecha y lugar concreto del fallecimiento, además de en muchos casos la edad, el origen, la residencia y la profesión de la víctima. Sin

42 También hubo víctimas en otras regiones de catalanas con hechos análogos a los de Barcelona: Esplugues, Vic, Sitges, Tarragona, Tortosa, Gerona, etcétera.

43 CRUELLS, 1970: 85-6. PEIRATS, 1988: 156. MARTÍNEZ BANDE, 1989: 268 (la primera edición se publicó en 1970).

44 SALAS LARRAZÁBAL, 1977: 185.

45 SOLÉ y VILLARROYA, 12 (Barcelona, 1982): 197-206.

46 GALLEGO, 2007: 486.

47 Payne tampoco lo cita y da la «posible» cifra de 400 víctimas mortales. PAYNE, 2010: 235. 
embargo, hay un dato que no se incluyó y nos parece esencial: la filiación de la víctima. Ello, obviamente, no podían ofrecerlo las fuentes que habían consultado así que nos propusimos el reto de revisar otras y completar el listado ${ }^{48}$.

El objetivo era separar a los miembros del bando llamado gubernamental: UGT, PSUC, JSU, ERC, Estat Català, Acció Catalana Republicana (ACR) y fuerza pública (Guardia Nacional Republicana, Guardia de Asalto, Agencia de Seguridad e Investigación y Mossos d'Esquadra); de los del bando revolucionario: CNT, FAI, Juventudes Libertarias, JCI y POUM ${ }^{49}$. El primer paso y, a priori, más fácil fue la identificación de la fuerza pública. El registro civil reveló a Solé y Villarroya que entre los fallecidos había 34 agentes pero un nuevo repaso minucioso a la prensa nos ha permitido encontrar a dos más, así que en total hubo 36. Los diarios publicaron mucha información sobre las víctimas y trataron de identificar a todas las que pudieron, así que hemos consultado los cinco periódicos que realizaron un mejor trabajo al respecto: $L a$ Vanguardia, Solidaridad Obrera, La Batalla, Treball y CNT de Madrid.

Los agentes eran fáciles de conocer por el uniforme, de ahí que el registro y los hospitales los identificaran, pero de los civiles sólo se dio alguna información. Gracias al diario del POUM, La Batalla, hemos podido saber el nombre de los cuatro fallecidos de este partido. ERC, Estat Català y ACR aportaron prácticamente la misma cantidad de hombres a la lucha que los poumistas y gracias a varias fuentes hemos sabido que sufrieron, al menos, el mismo número de víctimas que ellos. Concretamente, dos de ERC, uno de Estat Català y uno de ACR. Por otro lado, con el listado de Solé y Villarroya y la prensa hemos identificado a ocho víctimas colaterales de los combates: cuatro niños, una mujer de avanzada edad y tres sanitarios ${ }^{50}$. Con éstos, aún nos quedaba por saber la filiación de 166 personas.

48 Nos hemos ceñido a Solé y Villarroya pero hemos encontrado otras víctimas que no incluyeron en el listado como el anarquista Alfredo Martínez, que desapareció y todavía no se ha encontrado su cuerpo; los 12 libertarios cuyos cuerpos aparecieron días después en Cerdanyola; Francesc Ferrer, nieto de Ferrer i Guardia; el desconocido Francisco Tornero; y el Mosso d'Esquadra Francesc Ferrer i Prats. En CNT, 9 de junio de 1937, p. 2. Cartas de Abad de Santillán a Bolloten del 5 de noviembre y 25 de diciembre de 1971, HIA, Bolloten Collection, caja 5 carpeta 2. BONOMINI, 2006: 154. BROUÉ Y TÉMINE, 1962, vol. I: 339. La Batalla, 6 y 7 de mayo de 1937, p. 2. La Vanguardia, 7 de mayo de 1937, p. 2. Solidaridad Obrera, 8 de mayo de 1937, p. 10. Treball, 6 de mayo de 1937, p. 1. Front, 8 de mayo de 1937, p. 2. «Crònica diària de les activitats del President Companys: mes de maig».

${ }_{49}$ Las Patrullas de Control lucharon con los revolucionarios y estaban formadas en aquel momento sólo por miembros de la CNT, la FAI, las JJ.LL. y el POUM.

50 Es imposible saber si estos sanitarios fueron agredidos porque apoyaban a algún bando. El cenetista Balbino Coloma, testigo de los hechos, asegura que se colocaban ametralladoras en las ambulancias, aunque no hemos podido averiguar si era sólo para defenderse o para agredir a un bando determinado. La Cruz Roja de Barcelona declaró tras los sucesos que eran varios los sanitarios heridos y que no había ambulancia que no hubiera recibido algún balazo. 
La dificultad histórica era distinguir a los miembros de las organizaciones que aportaron más hombres a la lucha: la CNT-FAI, las Juventudes Libertarias, la UGT, el PSUC y las JSU. Las fuentes bibliográficas y la prensa sólo nos aportaron 12 anarquistas. En cuanto a los socialistas y comunistas, el AHPCE y el CDMH (Salamanca) guardan multitud de informes de militantes del PSUC y la UGT sobre su participación en los hechos que permiten reconstruir lo que sucedió casi al minuto pero apenas citan el nombre de alguna víctima ${ }^{51}$. Sólo pudimos confirmar a tres, uno de los cuales era teniente de la Guardia de Asalto (Manuel Fabras Ortega) y se ha clasificado como tal.

Así que todavía restaban por identificar 152. La única solución que nos quedaba era consultar un registro de militantes de cada organización y comparar. Acudimos a los archivos de las organizaciones en las que militaban y lo solicitamos pero la respuesta fue que no existían listados. Tanto el archivo del PCE como el de la CNT sólo tienen datos de dirigentes. Desconocemos si se llegaron a hacer listas completas de afiliados pero en cualquier caso se debieron destruir antes de que terminara la guerra para que no cayeran en manos de las autoridades franquistas ${ }^{52}$. Cuando parecía que no existía manera de resolver el asunto encontramos un «milagroso» documento en el archivo de Salamanca. Se trata de un listado realizado por las propias UGT, PSUC y JSU mediante el llamado «Comité de Ayuda a las víctimas de las jornadas de Mayo». En él aparecen los nombres de los muertos, heridos y desaparecidos durante los hechos que militaban en estas tres organizaciones. Hasta ahora nadie había reparado en este importante legajo porque, como suele ocurrir en estos casos, se guarda en una caja equivocada. Está clasificado en el apartado Político Social de Madrid cuando lo correcto es que estuviera en el de Barcelona ${ }^{53}$.

El documento ofrece una relación de 17 militantes de UGT-PSUC-JSU fallecidos, 17 desaparecidos y 48 heridos -15 de ellos policías-. El número de muertos es sólo uno menos que el que dio el cónsul ruso Antonov Ovseenko

Esta entidad montó 40 puestos de socorro en los que se realizaron 900 servicios entre muertos y heridos. Entrevista del autor a Balbino Coloma Atarés realizada el 11 de agosto de 2006 en su domicilio de Almudévar (Huesca). Solidaridad Obrera, 11 de mayo de 1937, p. 4. La Vanguardia, 7 de mayo de 1937, p. 2. La Batalla, 7 de mayo de 1937, p. 2.

51 Incluidos en la tesis doctoral del autor, La Sexta Columna. Enfrentamientos entre facciones antifascistas durante la Guerra Civil Española, defendida el 30 de marzo de 2009, Universidad CEU San Pablo, Facultad de Humanidades y CC. de la Comunicación.

52 En el AHPCE hay un listado con los miembros del Comité Central del partido en marzo de 1937 con una descripción de cada uno de ellos. En «Miembros del CC en marzo de 1937», AHPCE, Documentos PCE. Carpeta 18. El listado más amplio que hemos encontrado sobre los miembros de la CNT tiene 1.253 nombres y lo realizó Mariona Cardona Rosell para Bolloten. En Carta de Mariano Cardona del 29 de agosto de 1950 a Bolloten, HIA, Bolloten Collection, caja 5 carpeta 15.

53 «Relació de companys ferits, morts i desaparescuts», Comité d'Ajut a les víctimes de les jornades de Maig UGT-PSU-JSU, CDMH, PS Madrid, caja 540. 
en su informe «Sobre el putsch trotskista en Barcelona» del 21 de mayo de 1937. Aunque en él falta el secretario de la UGT catalana Antoni Sesé, que el cónsul sí debió contar. ${ }^{54}$ En nuestro propio recuento añadimos además a otro comunista que encontramos que no era policía: Miguel Caminal Navarro. ${ }^{55} \mathrm{El}$ listado de fallecidos que realizó este «Comité de Ayuda» es el siguiente:

\section{CUADRO 1: COMUNISTAS FALLECIDOS SEGÚN EL «COMITÉ DE AYUDA»}

\begin{tabular}{|c|c|c|c|}
\hline NOMBRE & DOMICILIO & SINDICAL & PARTIDO \\
\hline Josep Alcalde & Torrijos, 33 & UGT & JSU \\
\hline Salvador Ballester i Gil & Fernando Poo, 41 (Bajos) & UGT & \\
\hline Josep Ballestero & Av. República, 61 (Tordera L1.) & UGT & PSUC \\
\hline Josep Bosch Colomer & Fortuny, $2-3-2^{\mathrm{a}}$ & UGT & PSUC \\
\hline Antonio García Irastorza & Girona, 53 & UGT & \\
\hline José Javier Estruch & Viladomat, 52 ppal. $1^{\mathrm{a}}$ & CNT (sic) & PSUC \\
\hline Josep Lorenz Aguilar & Cerdenya, $51,2^{\circ} 3^{\mathrm{a}}$ & & PSUC \\
\hline Eulogi Miguel & Aray, $7,2^{\mathrm{a}}$ & & PSUC \\
\hline Rafael Moreno Altés & Ampla, 16, ppal. & UGT & \\
\hline Francesc Pahisa Ventura & & UGT & PSUC \\
\hline Josep Pallarés Aparicio & Eusebi Planes, $4,1^{\mathrm{a}}$ & UGT & \\
\hline Casimir Puigdemont Carrió & $\begin{array}{l}\text { C/ De la Pau, } 11 \text { (Pla del Besós } \\
\text { [Sant Adrià del Besós]) }\end{array}$ & UGT & ERC \\
\hline Carles Ribas i Ribas & Vilana & CNT (sic) & JSU \\
\hline Donato Rubio Herrera & Corts, $335,5,2^{\mathrm{a}}$ & & PSUC \\
\hline Antonia Sala Amorós & Amalia, $16,1^{\mathrm{a}}, 1^{\mathrm{a}}$ & UGT & \\
\hline Joaquín Sánchez Pascual & Masó, 32, $1^{\mathrm{a}}$ & UGT & \\
\hline Isidre Xurriguera & Muntaner, $183,3^{\circ}, 2^{\mathrm{a}}$ & UGT & \\
\hline
\end{tabular}

El primer paso era comparar estos nombres con los de Solé y Villarroya y el resultado arrojó algunas sorpresas. Todos coinciden menos tres: Salvador Ballester, Josep Ballestero y Joaquín Sánchez Pascual, los cuales no aparecen en la lista de Solé y Villarroya. La única explicación es que sus cuerpos no hubieran sido identi-

54 VIÑAS, 2007: 500.

55 «Informe de las bajas de la sección del batallón rojo de choque que presta sus servicios en La Pedrera», CDMH, PS Madrid, caja 540 (2) n 146. 
ficados en el Registro Civil y se les hubiera inscrito como «desconocidos». Debían de ser unas de las 28 víctimas sin nombre que hay en el listado Solé y Villarroya.

Por otro lado, Eulogio Miguel Leonor era guardia de asalto así que, al igual que Fabras Ortega, en nuestro propio inventario se ha clasificado como tal y no como militante del PSUC. Casimir Puigdemont también lo clasificamos como militante de ERC aunque lo era además de la UGT. A continuación abordamos a los que el comité apuntó como desaparecidos:

CUADRO 2: COMUNISTAS DESAPARECIDOS SEGÚN EL «COMITÉ DE AYUDA»

\begin{tabular}{|c|c|c|c|}
\hline NOMBRE & DOMICILIO & SINDICAL & PARTIDO \\
\hline Gonzal Aranda Rodríguez & & & PSUC \\
\hline Manel Gutiérrez García & & UGT & \\
\hline Enric Mateu Dijar & Parlament, $10,4^{\mathrm{o}} 2^{\mathrm{a}}$ & UGT & JSU \\
\hline Joan Moya Sánchez & Travessera Sant Martí, $360,7^{\circ} 1^{\mathrm{a}}$ & & JSU \\
\hline Víctor Nicueza Ibáñez & & UGT & PSUC \\
\hline Josep Rigol Pérez & $\begin{array}{l}\text { Príncep de Viana, } 6,2^{\circ} 2^{\mathrm{a}} \text {. (Divi- } \\
\text { sión Carlos Marx) }\end{array}$ & & \\
\hline Josep Seoane Rich & Rech Condal, $7,5^{\circ} 1^{\mathrm{a}}$ & UGT & PSUC \\
\hline Baldomer Tomás & Rocafort, $92,4^{\mathrm{o}} 1^{\mathrm{a}}$ & & \\
\hline \multicolumn{4}{|l|}{ Miguel Cergotal Pagés } \\
\hline \multicolumn{4}{|l|}{ Enric Blasco Tusquets } \\
\hline \multicolumn{4}{|l|}{ Pau Ramírez } \\
\hline \multicolumn{4}{|l|}{ Ramón Foraster } \\
\hline \multicolumn{4}{|l|}{ Emili Piquer } \\
\hline \multicolumn{4}{|l|}{ Josep Bartolomé } \\
\hline \multicolumn{4}{|l|}{ Joan Garriga Prats } \\
\hline \multicolumn{4}{|l|}{ Felip Caballero } \\
\hline Josep Sabana & & & \\
\hline
\end{tabular}

La comparación de estos nombres trajo todavía más sorpresas. Sólo hay dos que fueron registrados en el depósito de cadáveres: Gonzal Aranda Rodríguez y Joan Garriga Prats. Eso quiere decir que los otros 15 o no fueron identificados o no estaban muertos. Pero si el listado se hizo días después de terminar los combates... ¿Dónde podían estar?

Ambos bandos realizaron multitud de prisioneros durante la lucha y días después seguían sin liberar a la mayoría de ellos porque esperaban a que el 
«enemigo» lo hiciera primero. Gracias a un documento encontrado en el Archivo Nacional de Cataluña sabemos que era el caso de dos de los desaparecidos: Josep Seoane Rich y Josep Bartolomé. Eran militantes del radio XII del PSUC que habían sido detenidos por las Patrullas de Control el 8 de mayo en un control de la calle Gignàs con Regomir y no quedaron libres hasta que firmaron una declaración acusando a sus jefes de haber atacado a las patru1las ${ }^{56}$. En conclusión, tenemos tres nombres de fallecidos y 13 de desaparecidos afiliados a UGT, PSUC o JSU que pueden estar entre los 28 cuerpos sin identificar que hay en el listado de Solé y Villarroya.

De esta manera, tenemos reconocidos a los miembros de todas las facciones menos a los anarquistas y los independentistas. Teniendo en cuenta que, como hemos dicho, éstos últimos tuvieron un papel limitado, concluimos como hipótesis -conscientes de que puede haber un diminuto margen de errorque el resto de los fallecidos del listado de Solé y Villarroya, en total 110, eran afiliados o simpatizantes de la CNT, la FAI y las Juventudes Libertarias. A ellos habría que sumar los 12 de estas organizaciones que teníamos identificados y obtenemos el siguiente resultado:

\section{CUADRO 3: VÍCTIMAS POR FILIACIÓN}

\begin{tabular}{|l|l|}
\hline ORGANIZACIÓN & NÚMERO DE VÍCTIMAS \\
\hline CNT-FAI-JJLL & 122 \\
\hline Fuerza pública & 36 (2 de ellos militantes del PSUC) \\
\hline UGT-PSUC-JSU & 16 (+3 que no aparecen en listado Solé/Villarroya) \\
\hline ERC & 2 \\
\hline Estat Català & 1 \\
\hline Acció Catalana Republicana & 1 \\
\hline POUM & 4 \\
\hline Colaterales & 8 \\
\hline Nombre desconocido ${ }^{57}$ & 28 \\
\hline
\end{tabular}

56 Les obligaron a firmar una declaración acusando a sus jefes Chueca y Flores de dirigir un ataque contra las Patrullas de Control el día 3 de mayo que provocó 6 muertos y dos heridos graves. Declaración de los detenidos José Seoane y José Bartolomé Salvadó a la Sección $1^{\text {a }}$ de las Patrullas de Control. 12 de mayo de 1937, ANC, dossier «Fets de Maig», Fondo Generalitat de Cataluña (Segona República), nº 1, ingreso 1.614.

57 Si repartiéramos los 28 muertos de nombre desconocido proporcionalmente al número de bajas sufridas por cada bando quedarían 19 para los revolucionarios, 8 para los gubernamentales (que podrían ser los tres que no aparecen en el listado de Solé y Villarroya más cinco de la lista de desaparecidos) y una víctima colateral. El resultado obtenido es hipotético pero creemos que se ajusta bastante a la realidad: 145 víctimas revolucionarias, 64 gubernamentales y 9 colaterales. 
El saldo final demuestra que el bando revolucionario, sobre todo la CNTFAI-JJLL, sufrió más del doble de bajas que sus «enemigos»: 126 contra 56 sin contar los ocho colaterales y los 28 desconocidos-. Pero, ¿cómo pudo haber tanta desproporción en el número de víctimas? Conociendo cómo transcurrieron los combates las cifras encajan. Los informes inéditos realizados por los comunistas que antes hemos mencionado revelan que el bando gubernamental se mantuvo a la defensiva, atrincherado en edificios y barricadas, mientras que el revolucionario llevaba la iniciativa de los ataques. Lanzó numerosos asaltos contra edificios con el único parapeto de alguna tanqueta que acabaron en fracaso por la alta cantidad de bajas que sufría. Es algo que caracteriza a los combates urbanos. La defensa es relativamente fácil comparada con la ofensiva. No hay espacios abiertos para avanzar ni lugares donde resguardarse y con una sola ametralladora se puede defender una calle entera, por larga que sea.

Esta conclusión la comparte el propio Artemi Aiguadé, conseller de Interior durante los hechos, que declaró después de la guerra que los anarquistas habían sufrido la mayoría de las bajas del conflicto, aunque engordaba bastante las cifras: 1.500 muertos para los revolucionarios y un centenar escaso para el PSUC y la fuerza pública. El máximo responsable de la seguridad en la retaguardia catalana justificaba esta desproporción de bajas «por el hecho de que siempre tienen más pérdidas en esta clase de luchas los que tienen que atacar que los que se defienden parapetados». ${ }^{58}$ Antonov Ovseenko también concluyó en su informe que los comunistas caídos fueron muy pocos ${ }^{59}$.

Repasando el lugar de la muerte de cada una de las víctimas y cómo transcurrieron los combates sólo hay un caso que nos parece extraño. Miquel Salort Bosch, supuesto anarquista natural de Menorca y vecino de Barcelona, murió en la enfermería del Ayuntamiento de Barcelona el 4 de mayo, cuando aquello era una zona controlada completamente por los gubernamentales. Encaja muy bien como defensor de la Generalitat herido en uno de los ataques que sufrieron desde las Ramblas o la Plaza del Ángel, aunque también puede que hubiera sido detenido en los alrededores y asesinado en la plaza de Sant Jaume, como le ocurrió a De Peretti, Ferrari, Berneri y Barbieri, así que lo hemos mantenido como anarquista.

En cuanto a los heridos, la desproporción entre los bandos debió de ser parecida. No tenemos cifras definitivas, sólo el número de ingresados en los hospitales de Barcelona que publicó la prensa, así que son los únicos que se han utilizado en el Gráfico 1. Sin embargo, había casas de socorro y hospitales de campaña en las calles instalados por las organizaciones que atendieron

58 Entrevista de Jordi Arquer a Artemi Aiguadé, sin fecha, HIA, Stanford, Bolloten Collection, caja 87 carpeta 7 .

59 VIÑAS, 2007: 500. 
a muchos otros que no quedaron registrados «oficialmente». Según La Batalla, la suma de los heridos atendidos en los puestos de socorro del POUM entre el 3 y el 8 de mayo fue de $470^{60}$.

Otro aspecto que diferencia a los combates urbanos de los rurales es la rápida asistencia que reciben los heridos. Así se consigue rebajar el número de fallecidos. En Barcelona los sanitarios siguieron el protocolo de los bombardeos y realizaron un trabajo ejemplar. Cruells dice que actuaron «con un gran espíritu de sacrificio y de abnegación, y de este modo salvaron muchas vidas». ${ }^{61}$

GRÁFICO 1: LAS CIFRAS DE LOS HOSPITALES

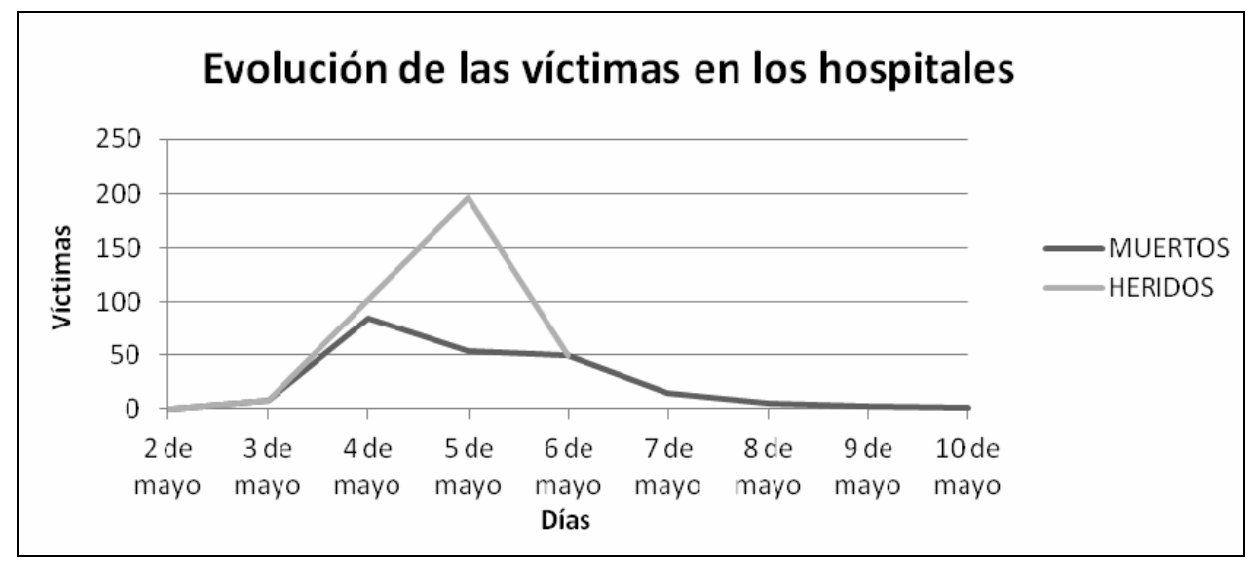

También se ha comparado el listado de Solé y Villarroya con los heridos que publicó la prensa los días 6,7 y 8 de mayo. Así hemos podido saber que 12 de ellos había recibido la herida mortal uno o varios días antes de morir. Los diarios utilizados para ello han sido principalmente La Vanguardia, La Batalla, y Solidaridad Obrera; y, en menor medida, Treball y La Humanitat por la escasa información que publicaron ${ }^{62}$. El resultado son unos cuadros estadísticos que reflejan de manera detallada cómo transcurrieron los combates para cada bando. Aunque los combates concluyeron el 8 de mayo, se incluyen las víctimas que se registraron hasta el día 10 porque se debieron a las represalias inmediatamente posteriores y porque el listado de Solé y Villarro-

60 La Batalla, 8 de mayo de 1937, p. 2.

61 CRUELLS, 1970: 86.

62 Todas estas colecciones han sido consultadas en el AHCB. 
ya así las tomó en cuenta. También hemos respetado la división por distritos de Barcelona que hicieron Solé y Villarroya.

Como se puede ver, el primer día de enfrentamientos sólo hubo ocho fallecidos: cuatro anarquistas en la zona de Universitat, un comunista en Sarrià, un guardia en Sant Martí Nord, un desconocido en Sa Llotja y una colateral en Gràcia: Luisa Picazo Deceguer, de 64 años. La dispersión y escaso número de víctimas demuestra que se trataba de disparos aislados entre grupos todavía pequeños. El segundo día fue el más violento, con 85 fallecidos. Los combates más duros se produjeron en Universitat y en Poble Sec. En el Paralelo tuvo lugar una de las mayores batallas de los Hechos de Mayo debido a la intervención de los anarquistas de Sants y un grupo expedicionario de guardias. Los revolucionarios eran más numerosos y contaban con artillería, lo que les permitió poner en fuga a sus enemigos. Este es uno de los pocos enfrentamientos en los que los revolucionarios sufrieron menos muertos que sus oponentes: 12 contra 14. No obstante, en Llotja y Universitat sufrieron este día muchísimas bajas en los intentos de asalto a edificios. El 5 de mayo baja el número de fallecidos a 53, casi la mitad de ellos anarquistas. Este día el POUM sufrió sus primeras dos víctimas mientras comunistas y fuerza pública no asumieron apenas riesgos debido a la llegada de los primeros refuerzos del Gobierno central. El día 6 el número de caídos se mantiene estable con medio centenar exacto. El descalabro del bando revolucionario es todavía mayor que en los días anteriores. Sufrieron 29 víctimas por sólo 8 de sus enemigos. El resto son 10 no identificadas y 3 colaterales. Los datos demuestran que los gubernamentales continuaban parapetados. Las jornadas del 7, 8, 9 y 10 de mayo confirman la tendencia y los gubernamentales dejan de sufrir víctimas mortales. De las 22 que se registran estos cuatro días, 16 son anarquistas y el resto no fueron identificadas. 
CUADRO 4: FALLECIDOS POR DISTRITOS Y FILIACIÓN EL 3 DE MAYO

\begin{tabular}{|c|c|c|c|c|c|c|c|c|c|}
\hline DÍA 3 & $\begin{array}{l}\text { CNT- } \\
\text { FAI }\end{array}$ & POUM & $\begin{array}{l}\text { UGT- } \\
\text { PSUC }\end{array}$ & $\begin{array}{c}\text { F. } \\
\text { pública }\end{array}$ & $\begin{array}{l}\text { ERC- } \\
\text { ACR }\end{array}$ & Desconocido & Colateral & & SUMA \\
\hline Llotja & & & & & & 1 & & & 1 \\
\hline Audiència & & & & & & & & & 0 \\
\hline Hospital & & & & & & & & & 0 \\
\hline Universitat & 4 & & & & & & & & 4 \\
\hline $\begin{array}{l}\text { Barceloneta- } \\
\text { Poble Nou }\end{array}$ & & & & & & & & & 0 \\
\hline $\begin{array}{l}\text { Gràcia- } \\
\text { Concepció }\end{array}$ & & & & & & & 1 & & 1 \\
\hline Poble Sec & & & & & & & & & 0 \\
\hline $\begin{array}{l}\text { Sant Martí } \\
\text { (Nord)-Sant } \\
\text { Andreu }\end{array}$ & & & & 1 & & & & & 1 \\
\hline Drassanes & & & & & & & & & 0 \\
\hline Sant Gervasi & & & & & & & & & 0 \\
\hline Sarrià & & & 1 & & & & & & 1 \\
\hline SUMA & 4 & 0 & 1 & 1 & 0 & 1 & 1 & TOTAL & 8 \\
\hline
\end{tabular}

CUADRO 5: FALLECIDOS POR DISTRITOS Y FILIACIÓN EL 4 DE MAYO

\begin{tabular}{|c|c|c|c|c|c|c|c|c|c|}
\hline DÍA 4 & $\begin{array}{c}\text { CNT- } \\
\text { FAI }\end{array}$ & POUM & $\begin{array}{l}\text { UGT- } \\
\text { PSUC }\end{array}$ & $\begin{array}{c}\text { F. } \\
\text { pública }\end{array}$ & $\begin{array}{l}\text { ERC- } \\
\text { ACR }\end{array}$ & Desconocido & Colateral & & SUMA \\
\hline Llotja & 11 & & 1 & 1 & & & & & 13 \\
\hline Audiència & 6 & & & & & & & & 6 \\
\hline Hospital & 1 & & & 2 & & 1 & 1 & & 5 \\
\hline Universitat & 16 & & 2 & 3 & & 1 & 1 & & 23 \\
\hline $\begin{array}{l}\text { Barceloneta- } \\
\text { Poble Nou }\end{array}$ & & & & 2 & & & & & 2 \\
\hline $\begin{array}{l}\text { Gràcia- } \\
\text { Concepció }\end{array}$ & & & & 2 & & 1 & & & 3 \\
\hline Poble Sec & 12 & & & 14 & & & & & 26 \\
\hline $\begin{array}{l}\text { Sant Martí } \\
\text { (Nord)-Sant } \\
\text { Andreu }\end{array}$ & 3 & & & & 1 & & & & 4 \\
\hline Drassanes & & & & & & & & & 0 \\
\hline Sant Gervasi & & & & & & & & & 0 \\
\hline Sarrià & & & & & & 3 & & & 3 \\
\hline SUMA & 49 & 0 & 3 & 24 & 1 & 6 & 2 & TOTAL & 85 \\
\hline
\end{tabular}


CUADRO 6: FALLECIDOS POR DISTRITOS Y FILIACIÓN EL 5 DE MAYO

\begin{tabular}{|l|c|c|c|c|c|c|c|c|c|}
\hline DíA 5 & $\begin{array}{c}\text { CNT- } \\
\text { FAI }\end{array}$ & POUM & $\begin{array}{c}\text { UGT- } \\
\text { PSUC }\end{array}$ & $\begin{array}{c}\text { F. } \\
\text { pública }\end{array}$ & $\begin{array}{c}\text { ERC- } \\
\text { ACR }\end{array}$ & Desconocido & Colateral & & SUMA \\
\hline Llotja & 5 & & & & & 1 & & & 6 \\
\hline Audiència & & & & & & & & & 0 \\
\hline Hospital & & & & 1 & & 1 & & & 2 \\
\hline Universitat & 5 & 1 & 1 & & 2 & 1 & 2 & & 12 \\
\hline $\begin{array}{l}\text { Barceloneta- } \\
\text { Poble Nou }\end{array}$ & 4 & & 1 & 2 & & & & & 7 \\
\hline $\begin{array}{l}\text { Gràcia- } \\
\text { Concepció }\end{array}$ & 5 & & & & & & & & 5 \\
\hline Poble Sec & 1 & & 1 & 5 & & 1 & & & 8 \\
\hline $\begin{array}{l}\text { Sant Martí } \\
\text { (Nord)-Sant } \\
\text { Andreu }\end{array}$ & 4 & 1 & 3 & 1 & & 1 & & & 10 \\
\hline Drassanes & & & & & & & & & 0 \\
\hline Sant Gervasi & 2 & & & & 1 & & & & 3 \\
\hline Sarrià & & & & & & & & & 0 \\
\hline & & & & & & & & & \\
\hline SUMA & 26 & 2 & 6 & 9 & 3 & 5 & 2 & TOTAL & 53 \\
\hline
\end{tabular}

CUADRO 7: FALLECIDOS POR DISTRITOS Y FILIACIÓN EL 6 DE MAYO

\begin{tabular}{|l|c|c|c|c|c|c|c|c|c|}
\hline DÍA 6 & $\begin{array}{c}\text { CNT- } \\
\text { FAI }\end{array}$ & POUM & $\begin{array}{c}\text { UGT- } \\
\text { PSUC }\end{array}$ & $\begin{array}{c}\text { F. } \\
\text { pública }\end{array}$ & $\begin{array}{c}\text { ERC- } \\
\text { ACR }\end{array}$ & Desconocido & Colateral & & SUMA \\
\hline Llotja & 1 & & & & & & 1 & & 2 \\
\hline Audiència & 3 & & 1 & & & & & & 4 \\
\hline Hospital & 4 & & 2 & & & 1 & 1 & & 8 \\
\hline Universitat & 3 & 1 & 2 & & & & 1 & & 7 \\
\hline $\begin{array}{l}\text { Barceloneta- } \\
\text { Poble Nou }\end{array}$ & 1 & & & & & & & & 1 \\
\hline $\begin{array}{l}\text { Gràcia- } \\
\text { Concepció }\end{array}$ & 2 & & & & & 4 & & & 6 \\
\hline Poble Sec & & & & & & & & & 0 \\
\hline $\begin{array}{l}\text { Sant Martí } \\
\text { (Nord)-Sant } \\
\text { Andreu }\end{array}$ & 9 & 1 & & 1 & & & & & 11 \\
\hline Drassanes & 2 & & 1 & 1 & & 2 & & & 6 \\
\hline Sant Gervasi & & & & & & & & & 0 \\
\hline Sarrià & 2 & & & & & 3 & & & 5 \\
\hline & & & & & & & & & \\
\hline SUMA & 27 & 2 & 6 & 2 & 0 & 10 & 3 & TOTAL & 50 \\
\hline
\end{tabular}


CUADRO 8: FALLECIDOS POR DISTRITOS Y FILIACIÓN EL 7 DE MAYO

\begin{tabular}{|c|c|c|c|c|c|c|c|c|c|}
\hline DÍA 3 & $\begin{array}{l}\text { CNT- } \\
\text { FAI }\end{array}$ & POUM & $\begin{array}{l}\text { UGT- } \\
\text { PSUC }\end{array}$ & $\begin{array}{c}\text { F. } \\
\text { pública }\end{array}$ & $\begin{array}{l}\text { ERC- } \\
\text { ACR }\end{array}$ & Desconocido & Colateral & & SUMA \\
\hline Llotja & & & & & & 2 & & & 2 \\
\hline Audiència & & & & & & & & & 0 \\
\hline Hospital & & & & & & 1 & & & 1 \\
\hline Universitat & 2 & & & & & & & & 2 \\
\hline Barceloneta-Po & ble Nou & & & & & 1 & & & 1 \\
\hline $\begin{array}{l}\text { Gràcia- } \\
\text { Concepció }\end{array}$ & 2 & & & & & & & & 2 \\
\hline Poble Sec & & & & & & & & & 0 \\
\hline $\begin{array}{l}\text { Sant Martí } \\
\text { (Nord)-Sant } \\
\text { Andreu }\end{array}$ & 3 & & & & & & & & 3 \\
\hline Drassanes & 2 & & & & & 1 & & & 3 \\
\hline Sant Gervasi & & & & & & & & & 0 \\
\hline Sarrià & & & & & & & & & 0 \\
\hline SUMA & 9 & 0 & 0 & 0 & 0 & 5 & 0 & TOTAL & 14 \\
\hline
\end{tabular}

CUADRO 9: FALLECIDOS POR DISTRITOS Y FILIACIÓN EL 8 DE MAYO

\begin{tabular}{|c|c|c|c|c|c|c|c|c|c|}
\hline DÍA 8 & $\begin{array}{c}\text { CNT- } \\
\text { FAI }\end{array}$ & POUM & $\begin{array}{l}\text { UGT- } \\
\text { PSUC }\end{array}$ & $\begin{array}{c}\text { F. } \\
\text { pública }\end{array}$ & $\begin{array}{l}\text { ERC- } \\
\text { ACR }\end{array}$ & Desconocido & Colateral & & SUMA \\
\hline Llotja & & & & & & & & & 0 \\
\hline Audiència & & & & & & 1 & & & 1 \\
\hline Hospital & & & & & & & & & 0 \\
\hline Universitat & 1 & & & & & & & & 1 \\
\hline $\begin{array}{l}\text { Barceloneta- } \\
\text { Poble Nou }\end{array}$ & & & & & & & & & 0 \\
\hline $\begin{array}{l}\text { Gràcia- } \\
\text { Concepció }\end{array}$ & 2 & & & & & & & & 2 \\
\hline Poble Sec & & & & & & & & & 0 \\
\hline $\begin{array}{l}\text { Sant Martí } \\
\text { (Nord)-Sant } \\
\text { Andreu }\end{array}$ & 1 & & & & & & & & 1 \\
\hline Drassanes & & & & & & & & & 0 \\
\hline Sant Gervasi & & & & & & & & & 0 \\
\hline Sarrià & & & & & & & & & 0 \\
\hline SUMA & 4 & 0 & 0 & 0 & 0 & 1 & 0 & TOTAL & 5 \\
\hline
\end{tabular}


CUADRO 10: FALLECIDOS POR DISTRITOS Y FILIACIÓN EL 9 DE MAYO

\begin{tabular}{|c|c|c|c|c|c|c|c|c|c|}
\hline DÍA 9 & $\begin{array}{l}\text { CNT- } \\
\text { FAI }\end{array}$ & POUM & $\begin{array}{l}\text { UGT- } \\
\text { PSUC }\end{array}$ & $\begin{array}{c}\text { F. } \\
\text { pública }\end{array}$ & $\begin{array}{l}\text { ERC- } \\
\text { ACR }\end{array}$ & Desconocido & Colateral & & SUMA \\
\hline Llotja & & & & & & & & & 0 \\
\hline Audiència & & & & & & & & & 0 \\
\hline Hospital & & & & & & & & & 0 \\
\hline Universitat & & & & & & & & & 0 \\
\hline $\begin{array}{l}\text { Barceloneta- } \\
\text { Poble Nou }\end{array}$ & & & & & & & & & 0 \\
\hline $\begin{array}{l}\text { Gràcia- } \\
\text { Concepció }\end{array}$ & & & & & & & & & 0 \\
\hline Poble Sec & & & & & & & & & 0 \\
\hline $\begin{array}{l}\text { Sant Martí } \\
\text { (Nord)-Sant } \\
\text { Andreu }\end{array}$ & & & & & & & & & 0 \\
\hline Drassanes & 1 & & & & & & & & 1 \\
\hline Sant Gervasi & 1 & & & & & & & & 1 \\
\hline Sarrià & & & & & & & & & 0 \\
\hline SUMA & 2 & 0 & 0 & 0 & 0 & 0 & 0 & TOTAL & 2 \\
\hline
\end{tabular}

CUADRO 11: FALLECIDOS POR DISTRITOS Y FILIACIÓN EL 10 DE MAYO

\begin{tabular}{|l|c|l|l|c|c|c|c|c|c|}
\hline DÍA 10 & $\begin{array}{c}\text { CNT- } \\
\text { FAI }\end{array}$ & POUM & $\begin{array}{c}\text { UGT- } \\
\text { PSUC }\end{array}$ & $\begin{array}{c}\text { F. } \\
\text { pública }\end{array}$ & $\begin{array}{c}\text { ERC- } \\
\text { ACR }\end{array}$ & Desconocido & Colateral & & SUMA \\
\hline Llotja & & & & & & & & & 0 \\
\hline Audiència & & & & & & & & & 0 \\
\hline Hospital & & & & & & & & & 0 \\
\hline Universitat & 1 & & & & & & & & 1 \\
\hline $\begin{array}{l}\text { Barceloneta- } \\
\text { Poble Nou }\end{array}$ & & & & & & & & & 0 \\
\hline $\begin{array}{l}\text { Gràcia- } \\
\text { Concepció }\end{array}$ & & & & & & & & & 0 \\
\hline Poble Sec & & & & & & & & & 0 \\
\hline $\begin{array}{l}\text { Sant Martí } \\
\text { (Nord)-Sant } \\
\text { Andreu }\end{array}$ & & & & & & & & & 0 \\
\hline Drassanes & & & & & & & & & 0 \\
\hline Sant Gervasi & & & & & & & & & \\
\hline Sarrià & & & & & & & & & \\
\hline
\end{tabular}


CUADRO 12: TOTAL FALLECIDOS POR DÍAS Y FILIACIÓN

\begin{tabular}{|l|c|c|c|c|c|c|c|c|c|}
\hline & $\begin{array}{c}\text { CNT- } \\
\text { FAI }\end{array}$ & POUM & $\begin{array}{c}\text { UGT- } \\
\text { PSUC }\end{array}$ & $\begin{array}{c}\text { F. } \\
\text { pública }\end{array}$ & ERC-ACR & Desconocido & Colateral & & SUMA \\
\hline 3 de mayo & 4 & & 1 & 1 & & 1 & 1 & & 8 \\
\hline 4 de mayo & 49 & & 3 & 24 & 1 & 6 & 2 & & 85 \\
\hline 5 de mayo & 26 & 2 & 6 & 9 & 3 & 5 & 2 & & 53 \\
\hline 6 de mayo & 27 & 2 & 6 & 2 & & 10 & 3 & & 50 \\
\hline 7 de mayo & 9 & & & & & 5 & & & 14 \\
\hline 8 de mayo & 4 & & & & & 1 & & & 5 \\
\hline 9 de mayo & 2 & & & & & & & & 2 \\
\hline 10 de mayo & 1 & & & & & & & & 1 \\
\hline & & & & & & & & & \\
\hline SUMA & 122 & 4 & 16 & 36 & 4 & 28 & 8 & TOTAL & 218 \\
\hline
\end{tabular}

GRÁFICO 2: TOTAL FALLECIDOS POR FILIACIÓN

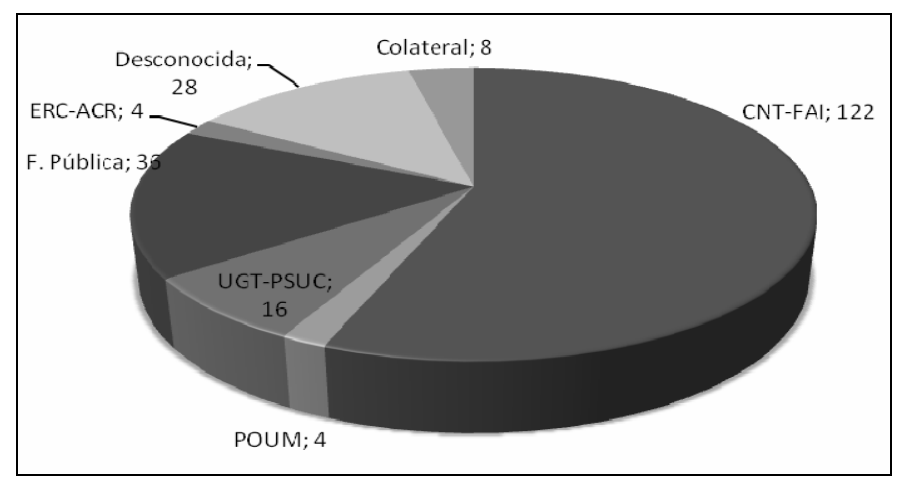

CUADRO 13: FALLECIDOS EN CADA BANDO POR DÍAS

\begin{tabular}{|c|c|c|c|c|c|c|}
\hline & Revolucionarios & Gubernamentales & Desconocidos & Colaterales & & SUMA \\
\hline 3 de mayo & 4 & 2 & 1 & 1 & & 8 \\
\hline 4 de mayo & 49 & 28 & 6 & 2 & & 85 \\
\hline 5 de mayo & 28 & 18 & 5 & 2 & & 53 \\
\hline 6 de mayo & 29 & 8 & 10 & 3 & & 50 \\
\hline 7 de mayo & 9 & & 5 & & & 14 \\
\hline 8 de mayo & 4 & & 1 & & & 5 \\
\hline 9 de mayo & 2 & & & & & 2 \\
\hline 10 de mayo & 1 & & & & & 1 \\
\hline SUMA & 126 & 56 & 28 & 8 & TOTAL & 218 \\
\hline
\end{tabular}


GRÁFICO 3: TOTAL FALLECIDOS POR DÍA Y BANDO

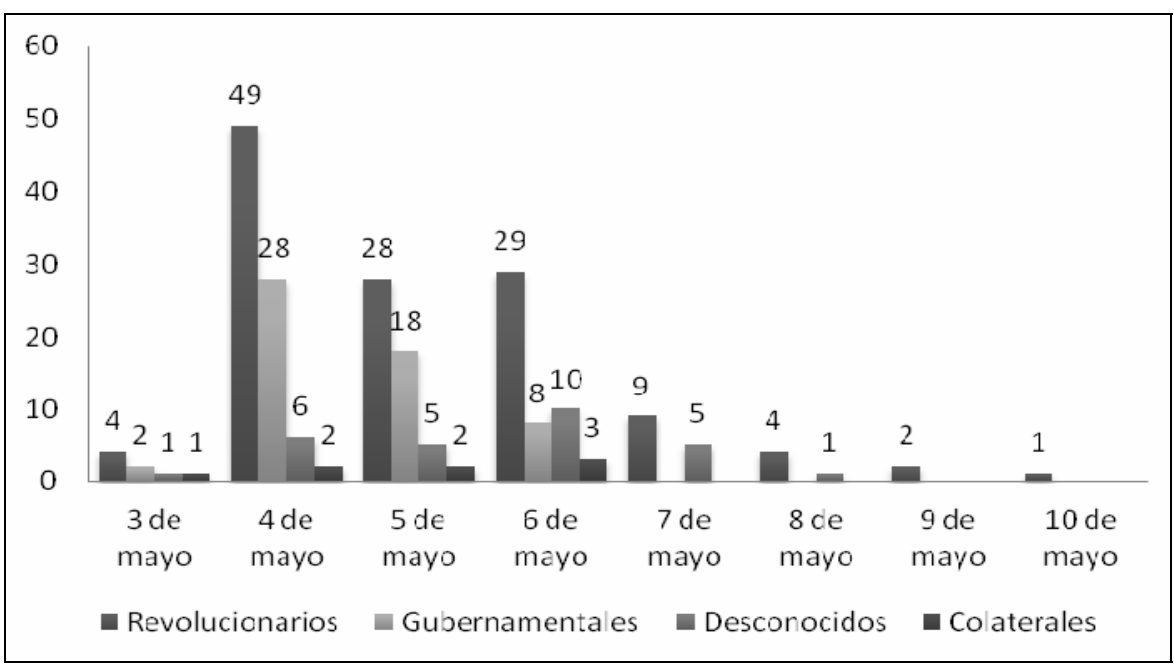

En conclusión, los Hechos de Mayo fueron un descalabro para los revolucionarios desde el punto de vista humano. Sufrieron más del doble de víctimas que sus enemigos. Los gubernamentales mantuvieron en general una posición defensiva que les dio resultado. Contaban con que tarde o temprano el Gobierno central les apoyaría así que se limitaron a defenderse desde sus parapetos y esperar la llegada de refuerzos. El único día que lanzaron una importante expedición fue el día 4 y ello provocó un duro combate en el Paralelo que se saldó con una derrota gubernamental y gran número de bajas por ambos bandos. A partir del día 5, los refuerzos del Gobierno central permitieron a los gubernamentales afianzarse en su estrategia defensiva.

Los revolucionarios controlaron casi toda la ciudad durante los Hechos pero fracasaron en asaltos clave como los del Hotel Colón (plaza Cataluña), el Casal Carlos Marx (Paseo de Gracia), cuartel Voroshilov (Parque de la Ciudadela) y Generalitat-Ayuntamiento (plaza de Sant Jaume). Estas operaciones les provocaron un goteo incesante de bajas que abarrotaron los hospitales de la ciudad. Al final, las soflamas pacifistas de sus líderes y la llegada masiva de refuerzos desde Valencia les obligaron a abandonar la lucha.

Además de las pérdidas humanas, las organizaciones CNT-FAI y POUM quedaron tocadas de muerte desde un punto de vista político. Los anarquistas salieron en los meses siguientes de los gobiernos central y catalán, se disolvieron las Patrullas de Control y los militantes más rebeldes sufrieron una dura represión. El caso del POUM fue mucho más allá. El partido fue declarado ilegal y sus líderes encarcelados. Su secretario general, Andreu Nin, fue 
torturado y ejecutado. François Godicheau ha investigado la represión contra los antifascistas en Cataluña y ha concluido que entre abril de 1937 y enero de 1939 llegaron a encarcelarse 3.734 militantes, el 90\% de los cuales era de la CNT, el 4\% del POUM, el 3\% de la UGT o PSUC y el resto de filiación desconocida $^{63}$. Las cifras evidencian que la organización con mayor número de militantes reprimidos fue la CNT-FAI.

\section{BIBLIOGRAFÍA}

Abad de Santillán, Diego, Por qué perdimos la guerra, Barcelona, Plaza \& Janés, 1977.

Aguilera Povedano, Manuel, Compañeros y camaradas. Las luchas entre antifascistas en la Guerra Civil Española, Madrid, Actas, 2012.

Aguilera Povedano, Manuel, "Causas de los sucesos de mayo de 1937 en Cataluña", en Alfonso Bullón de Mendoza y Luis Eugenio Togores, La República y la Guerra Civil Española sesenta años después, Madrid, Actas, 2008; 270-283.

Aguzzi, Aldo, "Un anarquista italiano en las Jornadas de Mayo", en Carlos García Velasco, H. Piotrowski, y Sergi Rosés (eds.), Barcelona, mayo 1937. Testimonios desde las barricadas, Barcelona, Alikornio, 2006; 155-162.

Aisa, Ferran, Contrarrevolució, Barcelona, 1984, 2007.

Amorós, Miquel, La revolución traicionada. La verdadera historia de Balius y los amigos de Durruti, Barcelona, Virus, 2003.

Bertrán y Musitu, José, Experiencias de los Servicios de Información del Nordeste de España (SIFNE) durante la guerra, Madrid, Espasa-Calpe, 1940.

Bolloten, Burnett, La Guerra Civil Española. Revolución y contrarrevolución, Madrid, Alianza Editorial, 2004.

Bonamusa, Francesc, "Els Fets de Maig del 37”, Documents 16, Barcelona, 1977.

Bonomini, Ernesto, "Semana sangrienta", en Carlos García Velasco, H. Piotrowski, y Sergi Rosés (eds.), Barcelona, mayo 1937. Testimonios desde las barricadas, Barcelona, Alikornio, 2006; 145-154.

Broué, Pierre, y Témine, Émile, La revolución y la guerra de España (I), México, Fondo de Cultura Económica, 1962.

Cruells, Manuel, Mayo sangriento. Barcelona 1937, Barcelona, Juventud, 1970.

Espinosa Maestre, Francisco (ed.), Violencia roja y azul, Barcelona, Crítica, 2010.

Gallego, Ferrán, Barcelona, mayo de 1937, Barcelona, Debate, 2007.

Gascón Ricao, Antonio, "Unidades Vasco Catalanas en La Guerra Civil Española". Disponible en http://www.sbhac.net/Republica/Fuerzas/EPR/EprD/VascoCatalanas.htm [octubre 2011].

63 GODICHEAU, 44 (Valencia, 2002): 39-63. 
Godicheau, François, "Los Hechos de Mayo de 1937 y los presos antifascistas: identificación de un fenómeno represivo", Historia Social 44 (Valencia, 2002): 39-63.

Guillamón, Agustín, Barricadas en Barcelona, Barcelona, Espartaco Internacional, 2007.

Hernández, Jesús, Negro y Rojo. Los anarquistas en la Revolución Española, México, La España Contemporánea, 1946.

Martín Ramos, José Luis, La reraguarda en guerra. Catalunya 1936-1937, Barcelona, L’Avenç, 2012.

Martín Ramos, José Luis, Els fets de maig, Barcelona, El viejo topo, 2010.

Martín Ramos, José Luis, "Història del sindicat UGT a Catalunya", diciembre de 2007. Disponible en: www.ugt.cat [noviembre de 2010]

Martínez Bande, José Manuel, La invasión de Aragón y el desembarco en Mallorca, Madrid, San Martín, 1989.

Mintz, Frank, y Peciña, Miguel, Los amigos de Durruti, los trosquistas y los sucesos de mayo, Madrid, Campo Abierto, 1978.

Mortera Pérez, Artemio, "La compañía de esquiadores de las Milicias Pirenaicas". Disponible en http:/www.nevasport.com/reportajes/art/31728/Esquiadores-en-laGuerra-Civil-Espanola-I/imprimir/ [octubre 2011]

Oehler, Hugo, "Barricadas en Barcelona: la primera revuelta del proletariado contra el Frente Popular capitalista: relato de un testigo. Barcelona, 15 de mayo de 1937', en Carlos García Velasco, H. Piotrowski, y Sergi Rosés (eds.), Barcelona, mayo 1937. Testimonios desde las barricadas, Barcelona, Alikornio, 2006; 29-56.

Olaya Morales, Francisco, El Oro de Negrín. Madrid, Nossa y Jara, 1998.

Orwell, George, Homenaje a Cataluña, Barcelona, Virus, 2000.

Payne, Stanley, ¿Por qué la República perdió la guerra?, Madrid, Espasa, 2010.

Peirats, José, La CNT en la Revolución Española, Cali, La Cuchilla, 1988.

Peiró, Joan, Perill a la reraguarda, Barcelona, Alta Fulla, 1987.

Preston, Paul, El holocausto español, Barcelona, Debate, 2011.

Radosh, R., Habeck M. R., Sevostianov G., España traicionada. Stalin y la guerra civil, Barcelona, Planeta, 2002.

Salas Larrazábal, Ramón, Pérdidas de la guerra, Barcelona, Planeta, 1977.

Sanchez Cervelló, Josep, ¿Por qué hemos sido derrotados? Las divergencias republicanas y otras cuestiones, Barcelona, Flor del Viento, 2006.

Sinca Vendrell, Amadeo, Lo que Dante no pudo imaginar, Barcelona, Producciones editoriales, 1980.

Solé, Josep, y Villarroya, Joan, "Les víctimes dels Fets de Maig”, Recerques, 12 (Barcelona, 1982): 197-206.

Souchy, Agustín, La verdad sobre los sucesos en la retaguardia leal. Los acontecimientos de Cataluña, Buenos Aires, FACA, junio de 1937.

Tafunell, Xavier, y Carreras, Albert, Estadísticas históricas de España: siglos XIXXX, Bilbao, Fundación BBVA, 2005. 
Téllez Solá, Antonio, La red de evasión del grupo Ponzán. Anarquistas en la guerra secreta contra el franquismo y el nazismo (1936-1944), Barcelona, Virus, 1996.

Torralba Coronas, Pedro, De Ayerbe a la "Roja y Negra”. 127 Brigada de la 28 División, Barcelona, edición del autor, 1980.

Viñas, Ángel, El escudo de la República, Barcelona, Crítica, 2007.

Recibido: 01-11-2011

Aceptado: 06-11-2012 